\title{
ICT extended social network for solving the peer and parental loneliness
}

\author{
Zhengke Fu1, Mengsi Yan 2 \\ 1Department of art and communication, Ningbo institue of technology, \\ Zhejiang University, Zhejiang, 315000, China \\ 2Department of Humanity, Ningbo Dahongying University, Zhejiang, \\ 315000, China
}

\begin{abstract}
At present, most of the researches on how might ICT impact well-being are focused on specific psychological result. This paper discusses how peer and parental loneliness might be affected by ICT mediated social network with the perspective of networked individualism and social captital theory. In order to solve the problem efficiently, we present a cross sectional study with the questionnaire to gain the data. As a result, people will combine EMAIL, IM, SNS to maintain their social network. In addition, the larger the mediated social network, the lower PEER AND PARENTAL loneliness. Whats more, the more friends in the EMAIL, IM, SNS friends, the lower PEER AND PARENTAL loneliness. Finally, the more family members in the EMAIL, IM, SNS, the higher PEER AND PARENTAL loneliness, and the more ordinary relationship in SNS, the lower the parent loneliness. The the result of the study indicates the assumption of the current study is effective and feasible.
\end{abstract}

Keywords: Networked individualism ,ICT,social capital,peer-parent loneliness

\section{Introduction}

How might ICT affect peoples life is a significant problem, which includes how ICT is used to extend peoples social network and how might it affect our psychological well being. Networked Individualism is a risen phenomenon in China. Urbanization has led to the passage of the community [1], and brought 
changes to the communication pattern. In China, the community model is shifting from the traditional closed communities to the individual centered community (Chang Jin, Zhang Dong et al. 2016) transition. And the traditional communication networks, which was composed of the interpersonal, group, organization, mass communication (Fei 2008), is replaced by the self-entered communication system enabled by the ICT[2].Scholars call this phenomenon networked individualism [3]. The consequences of the phenomenon,which occurring within the global scope raised concerns from multinational scholars.

Most of these studies focus only one specific ICT. The impact of ICT on social capital has been the focus of communication and sociology topics. A large number of empirical studies have shown, ICT use has significant impact on happiness [4-7] and social support[8].

There remains one puzzle need to be solved.Most of these theory usually takes the social psychology as one-dimension construct. For example, Although large number of empirical studies have shown, ICT use has a significant influence on happiness [4-7], social support [8] or even loneliness. the existing studies uesd to take social and psychological as single dimension construct [9], also, researchers on media and loneliness often used single dimension measurement $[8,10]$ to measure the concept, but from the ecological perspective, loneliness is multidimensional[11], there is need for researchers take it as a multidimensional concept [12], howerve, few studies have pointed out that internet or game usage is associated with multiple dimensions of specific social and psychological [13, 14], so how might ICT affect different kinds of loneliness ?

In this paper, based on the existing theory framework and sampling techniques[6], we propose the networked individualism and social capital theory to solve the questions, as how might ICT extended social network help to reduce the peer and parental loneliness. As a result, people will combine EMAIL, IM, SNS to maintain their social network. In addition, the larger the mediated social network, the lower PEER AND PARENTAL loneliness. Whats more, the more friends in the EMAIL, IM, SNS friends, the lower PEER AND PARENTAL loneliness. Finally, the more family members in the EMAIL, IM, SNS, the higher PEER AND PARENTAL loneliness, and the more ordinary relationship in SNS, the lower the parent loneliness.

The paper is organized as follows. In the next section, we propose the model that we research in this paper, and some definitions and assumptions are given. In Section 3, the explaination of how might ICT mediated social network could be used to reduce the peer and parental loneliness based on networked individualism theory is presented. In Section 4, the questionnaire based emperical study is carried out to illustrate the assumption of the study. Finally, we conclude our paper in section 5 .

\section{Discussed problems}

The discussed model is given as follow: 
Peerloneliness $=a+b_{1} x_{1}+b_{2}($ female $)+b_{3}($ education $)+b_{4}($ age $)$

Parentalloneliness $=a+b_{1} x_{1}+b_{2}($ female $)+b_{3}($ education $)+b_{4}($ age $)$

Some basic concepts associated with the problem are presented as follows Mediated social networks:

This is $\mathrm{X} 1$,which is the independent variable of interest. The mediated social network represents the quality and quantity of social relationship we carried out through ICT, like IM, SNS and email.

Peer loneliness:

This is Y1, which is the dependent variable of interest. The Peer loneliness represents the peer related loneliness situation of people.

Parental loneliness:

This is Y2, which is the second dependent variable of interest. The parental loneliness represents the parental related loneliness situation of people.

Background variables:

They are key demographic variables we added to control. The demographic variables includes sex, age and education.

\section{Definition 1}

For mediated social network, if the following conditions are satisfied:

i) people use ICT to connect with different type of social relationships;

Then, we called such social network as the mediated social network

\section{Definition 2}

For peer loneliness, if people answer the peer loneliness questionnaire,then we get his extent of peer related loneliness.

Definition 3

For parental loneliness, if people answer the parental loneliness questionnaire, then we get his extent of parental related loneliness.

Two assumptions are given as follows:

i) The mediated social network might significantly affect peer related loneliness

ii) The mediated social network might significantly affect parental related loneliness 


\section{The influence of ICT mediated social network on peer and parental loneliness}

\subsection{Social capital and muti-dimensional lonliness}

Social capital plays an important role on individual's Loneliness.Although there are many different definitions of social capital, but it contains one thing in common: They all concern the vital interests of social relations can bring, such as social support and companionship from the community. In this study, the definition of social capital is from the level of the individual, which is seen as social resources exist in individual social networks[15]. People are social animals, social networks or individual to provide various types of potential resources, which can bring benefits to the individual[16]. so the social capital has a very important role on people's mental and physical health. Maintaining social capital is a highly dynamic process, depending on the structure of social relationships and resources deriving[17, 18$]$.

In this study,Loneliness in this study was conceptualized as a negative experience, arising from lack of lack of ideal social relations in his or her social network. It is easy to think, different social relationships provides different social resources, which might affect different kinds of loneliness. So, the present study further take Loneliness as multi-dimensional experience.although there have been studies have indicated that loneliness has never been a single dimension of existence, it is necessary for different types of loneliness analyzed[19]. Taken together, these studies have pointed out the lack of social relations of different types are likely to have an impact on different types of loneliness. If other social relationships and loneliness defined as negative experience differences between individual expectations and social relations over social relations caused, which means that, for everyone, certain types of social relationships may be satisfied, It has not been met, so the perception of loneliness is different.

\subsection{ICT as the social support channel for the people in modern world}

Social network resources is helpful to reduce loneliness, but it is the media that makes the process possible. By using different types of modern media, selfcentered to build their own social network[3], through the interaction of different types of social relations, social networks and access to the resources they need [20], and on happiness, depression, social support [21] have an impact. By analyzing the relationship between social networks and ICT intermediary emotional, social loneliness will further clarify the mechanism of social capital impact of ICT production.

Media and social networks together have an impact on loneliness. Keep in touch with people through the use of different types of media and social networks in specific social relations and significantly affect social capital and happiness. IM, SNS, e-mail as the primary network communication tools, has a high penetration 
rate in China (CNNIC, 38th Statistical Report on China Internet Network Information Center, 2016.7) can be speculated that the three social media networks as intermediaries may have a significant impact on individual loneliness.

\section{Data gathering and analysis}

In order to illustrate the feasibility and effectiveness of the theory, we construct two studies according to examples in literature[22-25]. We solve them by using the regression analysis to answer the questions as how might mediated social network impact peer and parental loneliness.

The sampling process are set as follows:

By snowball sampling and third-party research platform,we get a nationally representative sample. The process carried out as follows:First, we select five cities: Ningbo, Hangzhou, Yangzhou, Beijing, Wuhan, to publish the questionnaires through seed investigators. Secondly, the "micro-survey" third party platform publish survey questionnaire Facing mainland china.Finally, we get 1075 cases. In all participants, 1033 people participated in the survey, participation rate was $96.1 \%$. After a pre-screening, only qualified data samples are included in the data analysis phase $(\mathrm{N}=995)$, the recovery rate was $96.32 \%$.

The measurement of variables are shown as follows:

The first part of the questionnaire asked participants to answer background information

The second part of the questionnaire used to obtain data mediation of social networks. According Tesung's research, mediation of social networks can be measured by two indicators: one is the size of social networks, the data is obtained by adding the total number of social networks in each media; the other is the intensity of social network relations, by getting the data of relationship type and the closeness of the relationship, we can calculate the strength of ties in the specific media. By modifying Tesung's mediated social networks questionnaire, the data of EMAIL,IM,SNS mediated social networks could be obtained through participants recalling the social relations ICT carried last week.

Peers and parents loneliness. By correcting UCLA loneliness questionnaire by Likert scale measuring loneliness condition of the individual, four topics ranging from 1 (strongly disagree) to 5 (strongly agree) score, the higher the score the higher the feeling of loneliness, Specific scale entry in Table 1.. 
Table 1 Rotated Factor matrics ${ }^{a}$

\begin{tabular}{|l|r|r|}
\hline & \multicolumn{2}{|c|}{ factor } \\
\cline { 2 - 3 } & 1 & \multicolumn{1}{|c|}{2} \\
\hline PRTL3 I wonder if parents really love me & .895 & \\
PRTL1 I feel parents will ignore my presence & .873 & \\
PRTL2 I find it difficult to communicate with their parents & .836 & \\
PEERL1 I think my friend, I feel less than others & & .848 \\
PEERL2 in between himself and the others kind of alienation & & .807 \\
PEERL3 I felt alone in school or company & & .611 \\
\hline
\end{tabular}

method : main factor analysis

ratation method : Kaiser max standard devation

To test the stability and the intrinsic validity of the questionnaire, the factor analysis and reliability analysis had been used,the result of the factor analysis is used to check the validity, table1 shows the questionnaire's validity is good.

As for the reliability of the peer and parental loneliness scale. Through the reliability analysis, internal consistency coefficient (Cronbachs' $\alpha$ ) of 0.896 , more than 0.7 , so the higher the internal consistency of each question item between related topics is greater than 0.3 , project-related amended greater than 0.5 , it questionnaire overall better reliability, the detail of the reliability test could be seen in table 2 and table 3.

Table 2 parent loneliness correlation matrix between scale items

\begin{tabular}{|c|c|c|c|}
\hline \multicolumn{3}{|c|}{ Item correlation } & Confidence efficience \\
\hline PRTL & 1 PRTL2 PRTL3 & $\begin{array}{l}\text { Corrected item } \\
\text { correlation }\end{array}$ & Cronbachs' $\alpha$ \\
\hline PRTL1 1.00 & & .80 & .90 \\
\hline PRTL2.72 & 1.00 & .77 & \\
\hline PRTL3 .78 & 1.00 & .81 & \\
\hline
\end{tabular}

Table 3 peer loneliness correlation matrix between scale items

\begin{tabular}{|c|c|c|c|c|}
\hline \multicolumn{3}{|c|}{ Item correlation } & \multicolumn{2}{|c|}{ Confidence efficience } \\
\hline \multicolumn{3}{|c|}{ PEERL1 PEERL2 PEERL3 } & $\begin{array}{l}\text { Corrected item } \\
\text { correlation }\end{array}$ & Cronbachs' $\alpha$ \\
\hline \multicolumn{3}{|c|}{ PEERL1 1.00} & .69 & .84 \\
\hline PEERL2 .69 & 1.00 & & .76 & \\
\hline PEERL 3.57 & .66 & 1.00 & .67 & \\
\hline
\end{tabular}


The impact of mediated social network on peer and parental loneliness are shown as follows:

Table 4 The impact of mediated social network on peer loneliness

\begin{tabular}{|c|c|c|c|c|c|c|c|c|c|c|c|c|c|c|}
\hline & \multicolumn{2}{|c|}{ MODLE1 } & \multicolumn{2}{|c|}{ MODLE2 } & \multicolumn{2}{|c|}{ MODLE3 } & \multicolumn{2}{|c|}{ MODLE4 } & \multicolumn{2}{|c|}{ MODLE5 } & \multicolumn{2}{|c|}{ MODLE } & \multicolumn{2}{|c|}{ MODLE7 } \\
\hline & $\beta$ & SE & $\beta$ & SE & $\beta$ & $\mathrm{SE}$ & $\beta$ & $\mathrm{SE}$ & $\beta$ & SE & $\beta$ & SE & $\beta$ & $\mathrm{SE}$ \\
\hline Edu & $-.14^{* *}$ & .04 & $-.15^{* *}$ & ** .04 & $-.14^{* * *}$ & ${ }^{*} .04$ & $-.14^{* *}$ & .04 & $-.14^{* * *}$ & .04 & $-.13^{* *}$ & .04 & $-.14^{* *}$ & ${ }^{*} .04$ \\
\hline Sex & .10 & .06 & .08 & .06 & .07 & .06 & .08 & .06 & .07 & .06 & .07 & .06 & .08 & .06 \\
\hline Age & -.05 & .03 & -.04 & .03 & -.04 & .03 & -.05 & .03 & -.04 & .03 & -.03 & .03 & -.05 & .03 \\
\hline Em1 num & & & $-.03^{* *}$ & 0.009 & & & & & & & & & & \\
\hline Im num & & & & & $-.07^{* *}$ & $* .01$ & & & & & & & & \\
\hline SNS num & & & & & & & -.04 & .01 & & & & & & \\
\hline Efml num & & & & & & & & & $.06^{* * *}$ & .03 & & & & \\
\hline Efrd num & & & & & & & & & $-.11^{* * *}$ & .02 & & & & \\
\hline Enrm num & & & & & & & & & .01 & .02 & & & & \\
\hline Ifml num & & & & & & & & & & & .02 & .02 & & \\
\hline Ifrd num & & & & & & & & & & & $-.12^{* *}$ & *.02 & & \\
\hline Inrm num & & & & & & & & & & & -.01 & .02 & & \\
\hline Sfml num & & & & & & & & & & & & & $.06^{* * *}$ & $* .02$ \\
\hline Sfrd num & & & & & & & & & & & & & $-.11^{*}$ & ${ }^{* *} .02$ \\
\hline Snrm num & & & & & & & & & & & & & -.01 & .02 \\
\hline $\mathrm{N}$ & & 995 & & 995 & & 995 & & 995 & & 95 & & 995 & & 995 \\
\hline $\begin{array}{l}\text { Adjusted } \\
\mathrm{R}\end{array}$ & & 017 & & 031 & & 058 & & 040 & & 47 & & 071 & & .060 \\
\hline
\end{tabular}

Table 5 The impact of mediated social network on parental loneliness

\begin{tabular}{|c|c|c|c|c|c|c|c|c|c|c|c|c|c|c|}
\hline & \multicolumn{2}{|c|}{ MODLE1 } & \multicolumn{2}{|c|}{ MODLE2 } & \multicolumn{2}{|c|}{ MODLE3 } & \multicolumn{2}{|c|}{ MODLE4 } & \multicolumn{2}{|c|}{ MODLE5 } & \multicolumn{2}{|c|}{ MODLE6 } & \multicolumn{2}{|c|}{ MODLE7 } \\
\hline & $\beta$ & $\mathrm{SE}$ & $\beta$ & SE & $\beta$ & SE & $\beta$ & $\mathrm{SE}$ & $\beta$ & SE & $\beta$ & SE & $\beta$ & SE \\
\hline Edu & .04 & .04 & .04 & .04 & .04 & .04 & .04 & .04 & .05 & .04 & .05 & .04 & .05 & .04 \\
\hline Sex & $-.10^{* * *}$ & .06 & $-.12^{* *}$ & .06 & $-.13^{* *}$ & .06 & $-.12^{*}$ & .06 & $-.12^{* *}$ & .06 & $-.13^{*}$ & .06 & $-.12^{* *}$ & .06 \\
\hline Age & $-.14^{* * *}$ & .03 & $-.14^{* * *}$ & .03 & $-.14^{* * *}$ & .03 & $-.14^{* * *}$ & .03 & $-.13^{* * *}$ & .03 & $-.13^{* * *}$ & .03 & $-.14^{* * *}$ & .03 \\
\hline Em1 num & & & $-.02^{* *}$ & .01 & & & & & & & & & & \\
\hline Im num & & & & & $-.06^{* * *}$ & .01 & & & & & & & & \\
\hline SNS num & & & & & & & $-.04^{* * *}$ & .01 & & & & & & \\
\hline Efm1 num & & & & & & & & & $.10^{* * * *}$ & .03 & & & & \\
\hline Efrd num & & & & & & & & & $-.07^{* * *}$ & .02 & & & & \\
\hline Enrm num & & & & & & & & & $-.04^{* *}$ & .02 & & & & \\
\hline Ifm1 num & & & & & & & & & & & .03 & .03 & & \\
\hline Ifrd num & & & & & & & & & & & $-.10^{* * *}$ & .02 & & \\
\hline Inrm num & & & & & & & & & & & -.02 & .02 & & \\
\hline
\end{tabular}




\begin{tabular}{|c|c|c|c|c|c|c|c|}
\hline Sfm1 num & & & & & & & $.13^{* * * *} .02$ \\
\hline Sfrd num & & & & & & & $-.09^{* * *} .02$ \\
\hline Snrm num & & & & & & & $-.07^{* * *} .02$ \\
\hline $\mathrm{N}$ & 995 & 995 & 995 & 995 & 995 & 995 & 995 \\
\hline $\begin{array}{l}\text { Adjusted } \\
\mathrm{R}\end{array}$ & .025 & .030 & .056 & .044 & .046 & .064 & .082 \\
\hline
\end{tabular}

As can be seen from table 4 and table 5, we use the social network in the email, instant messaging and social media as predictors.

Model 2 to 4 show email, instant messaging network, social media network negativly impact PEER AND PARENTAL Loneliness significant, which shows that the larger social networks in email, instant messaging and social media networks, the lower PEER AND PARENTAL loneliness.

Model 5 to 7 measuring link between the different types of social relations in each media channels and loneliness. It shows that the more close friends in email,, instant messaging networks, social media networks, the lower PEER AND PARENTAL Loneliness, while the Internet, the more family member in social media networks, The higher PEER AND PARENTAL loneliness.

\section{Conclusions}

In this study, the problem of how might ICT affect different kind of loneliness is been answerd by the framework combining the social capital, social network and networked individualism theory. The major advantage of this theory framework is that it shows the complex mechanism between ICT usage and multidimensional psychological phenomenon. Hence, it can be used as a foundation to explore how ICT impact our social life in the future studies.

\section{Acknowledgements}

The research work was supported by Zhejiang Federation of Humanities and Social Sciences Circles under Grant No. 2015N033, Zhejiang Provincial Department of Culture under Grant No. 2011-z-756 and Zhejiang Provincial Department of education.

\section{References}

1. Park, R.E., The city: Suggestions for the investigation of human behavior in the city environment. The American Journal of Sociology, 1915. 20(5): p. 577-612.

2. Boase, J., Personal networks and the personal communication system: Using multiple media to connect. Information, communication \& society, 2008. 11(4): p. 490-508. 
3. Wellman, B., Little boxes, glocalization, and networked individualism, in Digital cities II: Computational and sociological approaches. 2001, Springer. p. 10-25.

4. Cummings, J., J. Lee, and R. Kraut, Communication technology and friendship during the transition from high school to college. Computers, phones, and the Internet: Domesticating information technology, 2006: p. 265-278.

5. Anderson, B. and K. Tracey, Digital Living The Impact (or Otherwise) of the Internet on Everyday Life. American behavioral scientist, 2001. 45(3): p. 456-475.

6. Ofcom, Social networking: A quantitative and qualitative research report into attitudes, behaviours and use. 2008, Office of Communications, UK London.

7. Tong, S.T., et al., Too much of a good thing? The relationship between number of friends and interpersonal impressions on Facebook. Journal of Computer - Mediated Communication, 2008. 13(3): p. 531-549.

8. Vergeer, M. and B. Pelzer, Consequences of media and Internet use for offline and online network capital and well - being. A causal model approach. Journal of Computer - Mediated Communication, 2009. 15(1): p. 189-210.

9. Cacioppo, J.T., et al., Loneliness as a specific risk factor for depressive symptoms: cross-sectional and longitudinal analyses. Psychology and aging, 2006. 21(1): p. 140.

10. Leung, L., Stressful life events, motives for Internet use, and social support among digital kids. CyberPsychology \& Behavior, 2006. 10(2): p. 204-214.

11. Chipuer, H.M., Dyadic attachments and community connectedness: Links with youths' loneliness experiences. Journal of Community Psychology, 2001. 29(4): p. 429-446.

12. Jr, J.M.G., et al., LONELINESS, DEPRESSION, STRESS, AND SOCIAL SUPPORTS IN NEGLECTFUL FAMILIES. American Journal of Orthopsychiatry, 1993. 63(4): p. 597-605.

13. $\mathrm{Hu}, \mathrm{M} .$, Will online chat help alleviate mood loneliness? CyberPsychology \& Behavior, 2009. 12(2): p. 219-223.

14. Weiss, R.S., Loneliness: The experience of emotional and social isolation. 1973.

15. Wellman, B., The network is personal: Introduction to a special issue of Social Networks. Social networks, 2007. 29(3): p. 349-356.

16. Lin, N., Building a network theory of social capital. Connections, 1999. 22(1): p. 28-51.

17. Granovetter, M., Getting a job: A study of contacts and careers. 1995: University of Chicago Press.

18. Lin, N., Social capital: A theory of social structure and action. Vol. 19. 2002: Cambridge university press. 
19. Peplau, L.A., M. Miceli, and B. Morasch, Loneliness and self-evaluation. Loneliness: A sourcebook of current theory, research and therapy, 1982: p. 135-151.

20. Wellman, B. and K. Frank, Network capital in a multilevel world: Getting support from personal communities. Social capital: Theory and research, 2001: p. 233-273.

21. Eastin, M.S. and R. LaRose, Alt. support: Modeling social support online. Computers in Human Behavior, 2005. 21(6): p. 977-992.

22. Löfgren, O., The nation as home or motel? Metaphors of media and belonging. Sosiologisk Årbok, 2001. 14(1): p. 1-34.

23. Tseng, S.-F. and Y.P. Hsieh, The Implications of Networked Individualism for Social Participation How Mobile Phone, E-mail, and IM Networks Afford Social Participation for Rural Residents in Taiwan. American Behavioral Scientist, 2015: p. 0002764215580620.

24. Valkenburg, P.M. and J. Peter, Internet communication and its relation to well-being: Identifying some underlying mechanisms. Media Psychology, 2007. 9(1): p. 43-58.

25. Wang, H., V. Chua, and M.A. Stefanone, Social Ties, Communication Channels, and Personal Well-Being A Study of the Networked Lives of College Students in Singapore. American Behavioral Scientist, 2015: p. 0002764215580590. 